\title{
Health Extension and Clinical and Translational Science: An Innovative Strategy for Community Engagement
}

\author{
Arthur Kaufman, MD, Robert L. Rhyne, MD, Juliana Anastasoff, MS, \\ Francisco Ronquillo, PA, Marnie Nixon, MA, Shiraz Mishra, MBBS, PhD, \\ Charlene Poola, LISW, Janet Page-Reeves, PhD, Carolina Nkouaga, \\ Carla Cordova, MPH, and Richard S. Larson, MD, PhD
}

Health Extension Regional Officers (HEROs) through the University of New Mexico Health Sciences Center (UNMHSC) help to facilitate university-community engagement throughout New Mexico. HEROs, based in communities across the state, link priority community health needs with university resources in education, service, and research. Researchers' studies are usually aligned with federal funding priorities rather than with health priorities expressed by communities. To help overcome this misalignment, the UNM Clinical and Translational Science Center (CTSC) provides partial funding for HEROs to bridge the divide between research priorities of UNMHSC and health priorities of the state's communities. A bidirectional partnership between HEROs and CTSC researchers was established, which led to: 1) increased community engaged studies through the CTSC, 2) the HERO model itself as a subject of research, 3) a HEROdriven increase in local capacity in scholarship and grant writing, and 4) development of training modules for investigators and community stakeholders on community-engaged research. As a result, 5 grants were submitted, 4 of which were funded, totaling $\$ 7,409,002.00$, and 3 research articles were published. Health extension can serve as a university-funded, community-based bridge between community health needs and Clinical and Translational Science Award (CTSA) research capacity, opening avenues for translational research. (J Am Board Fam Med 2017;30:94-99.)

Keywords: Grants, Health Priorities, New Mexico, Research Personnel, Translational Medical Research, Universities, Writing

This article was externally peer reviewed.

Submitted 8 April 2016; revised 30 September 2016; accepted 5 October 2016.

From the Office for Community Health, University of New Mexico Health Sciences Center, Albuquerque, NM.

Funding: This project was supported in part by the National Center for Research Resources and the National Center for Advancing Translational Sciences of the National Institutes of Health through Grant Number UL1 TR000041. The content is solely the responsibility of the authors and does not necessarily represent the official views of the NIH.

Conflict of interest: none declared.

Corresponding author: Arthur Kaufman, MD, University of New Mexico Health Sciences Center, MSC 09 5065, 1 University of New Mexico, Albuquerque, NM 87131 (Email: akaufman@salud.unm.edu).

See Related Commentary on page 10.
The national movement to more rapidly translate science to clinical practice has brought greater emphasis to the collaboration between researchers and communities. The National Institutes of Health recognized the need to incorporate community engagement into research when it created the CTSAs in 2006 and included community-engaged research as a primary focus. ${ }^{1}$ In its 2013 analysis of the CTSA program, the Institute of Medicine recommended that community engagement be ensured in all phases of clinical and translational research, citing a need for community stakeholders to partner in a bidirectional manner with CTSAs to identify health priorities, to provide critical input and decision making across all phases of research, to help develop ethically and culturally appropriate research protocols, to help promote enrollment and retention of study participants, and to disseminate and implement study results more effectively. ${ }^{1}$ 
Practice-Based Research Networks ${ }^{2}$, Bootcamp Translation $^{3}$, and Community-Based Participatory Research $^{4}$ are some of the strategies that have evolved to engage local practitioners and community members in the research enterprise. Bootcamp translation takes evidence-based clinical practice guidelines and trains community stakeholders to become health topic experts who then work with the research team to 1) develop culturally and contextually relevant messaging, 2) identify ways to disseminate those messages, and 3) change local and community conversations about the health topic through their active participation in the bootcamp translation process. ${ }^{3}$ The Health Extension program is another strategy that could be effective in the research translation process. These strategies and others designed to increase clinical and translational research in community populations will invariably involve local primary care practices more in research; they are often the community's principal connection to the entire health care system.

Section 5405 of the Affordable Care Act authorized the Primary Care Extension Program (PCEP), for which pilot funding was provided by the Agency for Health care Research and Quality (AHRQ) through its Infrastructure for Maintaining Primary Care Transformation (IMPaCT) grants. ${ }^{5}$ PCEP applied aspects of the agricultural Cooperative Extension Service model $^{6}$ to facilitate transformation toward patient-centered medical homes and the Triple AIM of small, primary care practices. Ultimately, 18 states were involved in the PCEP grant consortium, each applying the concept of "extension" to small primary care practice transformation in unique ways captured on an on-line toolkit. ${ }^{7}$ The health extension regional officer (HERO) model is designed to link community health priorities with academic resources in all mission areas, including education, research, and service. The HERO program and CTSAs have a common goal with the PCEP of facilitating primary care practice transformation by performing more community engaged research and disseminating the latest research best practices to providers and community members.

\section{The HERO Program}

The HERO program was a model of health extension created some years before the Affordable Care Act and patterned after the U.S. Department of Agriculture's county-based agricultural Coopera- tive Extension Service. ${ }^{8}$ Each state's Cooperative Extension Service is operated by their land grant university, responding to priority needs of agricultural communities by extending new knowledge and technologies to improve agricultural practices and family life. ${ }^{9}$

The HERO program was created at the UNMHSC in 2008. It hires "agents" (known as "HEROs") with master's level education, with experience in some aspect of health systems, and with extensive community engagement experience. HEROs live in the communities they serve and link their community's health priorities with a range of UNMHSC resources. Because community health is more a reflection of social and economic factors than health services ${ }^{10}$, HEROs engage locally with a broad set of stakeholders, including the health system (primary care practices, community health centers, community hospitals) as well as other community sectors, such as colleges and schools, faithbased organizations, and civic organizations. UNMHSC currently employs 12 HEROs who cover all geographic areas of the state and reflect the ethnic diversity of their communities.

\section{Challenges: Community versus Academic Goals}

Focus groups held in 2008 across New Mexico found that researchers at UNMHSC were perceived by the public as lacking a long-term commitment and sensitivity to communities they studied and that the benefit of research was unidirectional, serving the needs of researchers rather than communities. ${ }^{11}$ Further, health priorities identified by local community members differed greatly from the research priorities of the researchers at the academic health center (Table 1).

Embedded in the communities in which they lived and served, HEROs felt a need to protect their communities from negative interactions with researchers. These interactions could include disrespectful behavior, failure to consult with community leaders, or being perceived as using the community without giving back anything of value. Such behavior would leave HEROs in a compromised position after the researcher left.

And participation in research was rarely a community's priority. Access to clinical services, educational opportunities, and addressing adverse social determinants were far more pressing. So 
Table 1. Comparison of Community Health Priorities versus Academic Research Priorities

\begin{tabular}{ll}
\hline $\begin{array}{l}\text { Community Health Priorities } \\
\text { Established by County and } \\
\text { Tribal Councils in } 2012\end{array}$ & $\begin{array}{c}\text { UNM Health Sciences } \\
\text { Research Priorities } \\
\text { "Signature Programs" }\end{array}$ \\
$\begin{array}{l}\mathrm{N}=33 \text { counties in New } \\
\text { Mexico) }\end{array}$ & Established in 2005 \\
$\begin{array}{l}\text { Substance abuse, } \mathrm{N}=20 \\
\text { Teen pregnancy, } \mathrm{N}=16\end{array}$ & $\begin{array}{l}\text { Cancer } \\
\text { Cardiovascular and Metabolic } \\
\text { Diseases }\end{array}$ \\
Access to care, $\mathrm{N}=15$ & $\begin{array}{c}\text { Brain and Behavior } \\
\text { Infectious Disease and } \\
\text { Violence, } \mathrm{N}=11\end{array}$ \\
Immunity \\
Obesity, $\mathrm{N}=11$
\end{tabular}

Community versus Academic Health Center Priorities: Established Independently.

UNM, University of New Maxico.

HEROs were challenged to help researchers connect their study proposals in meaningful ways to the felt needs of their communities.

Academic researchers at the CTSC in general did not understand how to best approach communities where they sought to perform their studies. Specifically, they did not understand how to approach, educate, or build a trusting relationship that is necessary before research can be performed. And researchers in the past have characteristically not presented the research results back to the community, which engendered resentment among community members.

To address these concerns, the HERO program and the Clinical and Translational Sciences Center (CTSC) at UNMHSC, which was initially funded in 2010, formed a partnership designed to capital- ize on each other's strengths in developing a research partnership with communities, generating bidirectional benefits.

\section{HEROs and CTSC: The Partnership as a Solution to the Challenges}

To build the partnership between HEROs and CTSC, an agreement was negotiated in 2012 that specified each partner's contribution (Table 2). Monthly meetings were conducted to plan and review joint projects. The CTSC provided partial salary support for HEROs that assured a statewide liaison function between HEROs and academic researchers. Specific clinical research projects were developed that addressed both community and researcher's topical priorities. Research training modules were developed for HEROs and community stakeholders.

HEROs' familiarity with local strengths and contexts provided researchers with more effective community engagement research strategies. They developed a community-based process to identify regional health priorities and issues that may benefit from CTSC pilot funding. HEROs acted as liaisons for and joined specific project research teams conducting research in their regions. As a result, HEROs participated directly in research projects. They assisted in recruiting study participants and also recruited researchers for community-driven health initiatives. They consented participants, performed research coordination, implemented educational (dissemination) interventions as academic detailers, and served as coinvestigators on some studies.

Table 2. CTSC-HERO Complementary Partnership Roles to Improve Community Engaged Research and Health Outcomes

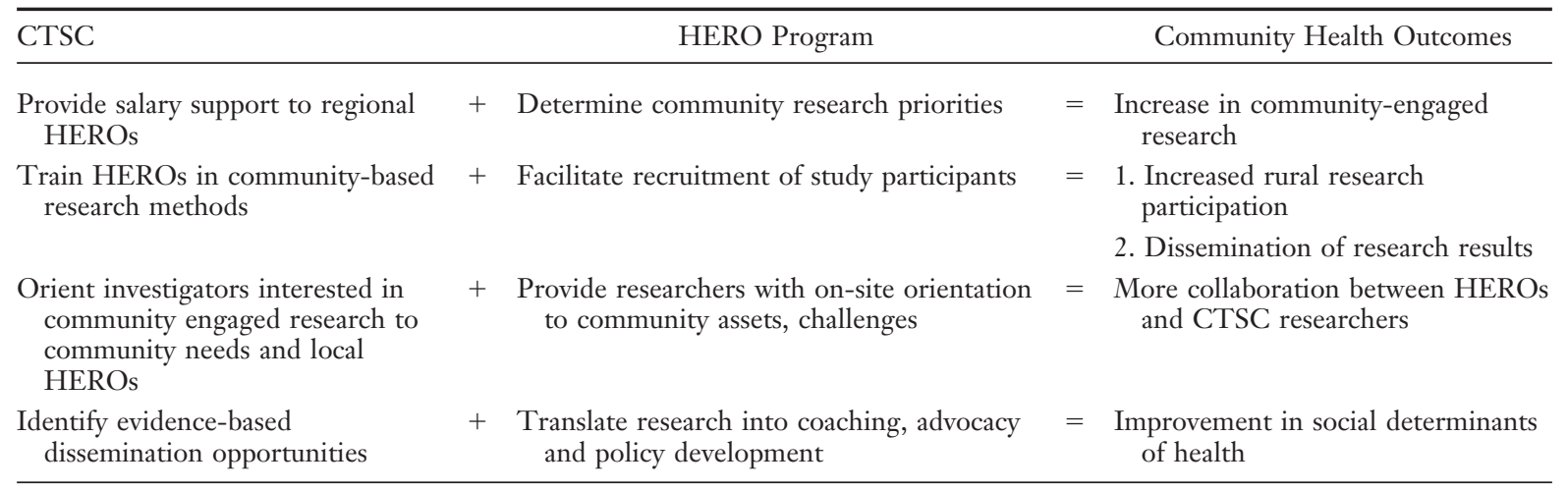

CTSC, Clinical and Traslational Science Center; HERO, Health Extesion Regional Officers. 
Challenge: Overcoming Researchers' Outsider Status

Researchers often feel like and are considered outsiders in communities, even though they have good intentions and funding to perform research in communities. Projects were developed and funded to investigate best practices for disseminating evidence-based information to rural primary care providers and community members. In 1 example, a researcher was funded to conduct a study on obesity in teens in a rural school system. As an outsider unfamiliar with the school hierarchy, key decision makers, local school priorities and constraints, she was unsuccessful in recruiting study subjects and actually created some angst between the researchers and the school system leadership because her team did not know how to approach the proper chain of leadership command. She sought help from the UNMHSC CTSC Office, which connected her with the local HERO. That HERO had worked closely with the school system and knew well the school leadership personally and professionally. She took personal responsibility for reintroducing the researcher to the school leaders and parents and helped explain the link between her study and the growing epidemic of obesity among the school's teens. The study was then allowed to proceed, generating important outcomes.

\section{Challenge: Incorporating HEROs into the Research Process}

HEROs often do not understand the research process and are skeptical of the benefits of research. An example of how to overcome this challenge occurred when a study team involved a local HERO working on a UNMHSC study exploring strategies for helping rural primary care clinics adopt evidence-based practices in prescribing opioids for chronic noncancer pain. In this case the HERO, who knew the personnel in the local clinics well, was trained by the research team in the skills of academic detailing. As a trusted member of the community, she had easy access to the clinics and was able to deliver a key portion of the intervention to clinic staff, and became an integral member of the research team.

\section{Challenge: Overcoming Cultural Barriers}

HEROs reflect the ethnic and linguistic diversity of their region and this attribute can facilitate a mutually beneficial link between community and researcher. Access to health care is a major barrier in
Hispanic communities. A CTSC-funded pilot project addressed barriers to accessing health care $^{12}$ using health literacy as a vehicle for teaching English as a second language to Spanish speakers. A HERO who is skilled in teaching health literacy within Hispanic populations was successful in helping the researcher identify and coordinate project sites, conduct focus groups, and recruit participants for the study.

\section{Challenge: Motivating Researchers to Address Local Health Priorities}

Access to behavioral health services is severely lacking in New Mexico, especially in rural areas. Responding to this community-identified priority, a HERO worked with a UNMHSC Department of Psychiatry faculty member to secure funding to host national leaders to train trainers in Mental Health First Aid, a course for "first responders" to help alleviate mental health service gaps. As a result, hundreds were trained, including medical office staff and community health workers. The HERO then identified a CTSC funding opportunity and recruited a UNMHSC researcher to study barriers in disseminating the training in rural areas. $^{13}$

\section{Challenge: Evidence the HERO-CTSC Model is Successful in Generating Grant Support}

Several projects have been funded to study the effectiveness of the HERO model in conducting community-engaged research. The HERO program has led a growing national movement of various health-extension models across the country. ${ }^{7}$ Facilitation of this dissemination has been funded by the AHRQ (Award No. 1U18HS020890) and by the Commonwealth Fund (Award No. 20110082 and 20130647). CTSC researchers collaborated with HEROs on an AHRQ grant to use HEROs as academic detailers to study the efficacy of disseminating evidence-based information on the treatment of patients with chronic noncancer pain to rural primary care providers (Award No. R24 HS022033 to 01). This method is now being used in a U.S. Center for Disease Control and Prevention grant to the Department of Health to disseminate that program to all opioid prescribers in the state, using a HERO as an academic detailer. A second AHRQ-funded project underway is assessing the efficacy of HEROs partnering with practice facilitators and information technology consultants 
to improve primary care adoption and reporting of cardiovascular disease guidelines in preparation for value-based reimbursement (EvidenceNow Award No. R18 HS023904 to 01).

\section{Outcomes of the HEROs and CTSC Partnership}

After 2 years, 6 grants have been submitted as a result of the partnership and 5 were funded, totaling \$7,409,002 (NIH R01: \$3,506,393; AHRQ R18: \$848,284; AHRQ R18: \$3,000,000; 2 CTSC pilots: $\$ 54,325)$ and 3 articles were published. . $^{82,13}$ New Mexico received a State Innovations Model Design Award from the Centers for Medicare and Medicaid Services. The resulting plan designated HEROs as key regional resources in facilitating links between priority community health needs and health system and social service resources.

Finally, the CTSC-HERO partnership led to a plan for greater community engagement in research in the successful 5-year CTSC renewal award funded in 2015. The CTSC created a Community Health Specialist position whose responsibility it is to work with HEROs in developing better methods of recruiting rural populations for translational research, improving the connection between the CTSC and New Mexico communities, and helping establish community-university partnerships.

\section{Discussion}

Despite success with the HEROs-CTSC partnership, challenges remain. HEROs, because of their intimate knowledge of the community and the local trust they have built, are valuable resources for researchers who do not feel comfortable navigating communities with which they are unfamiliar. Yet, HEROs are held accountable by communities in research activities they promote, which makes them vulnerable to local criticism if researchers are unresponsive to community expectations and needs. To make this partnership successful and sustainable, researchers must appreciate the vulnerabilities HEROs face in acting as liaisons between an academic institution and communities. HEROs are placing their longstanding professional and personal community relationships at risk if problems between researchers and communities arise. One solution to this challenge is to incorporate HEROs into the research team as a broker between com- munity health priorities and researcher capacities while playing a more active role in the research process, that is, as a research coordinator, recruiter, or academic detailer.

The health extension model is a growing phenomenon in the United States, with at least 18 states now piloting different aspects of the model. ${ }^{7,14}$ HEROs are playing many roles in health care, from primary care transformation to community health improvement. ${ }^{8}$ However, their role in promoting community-engaged research is new. Health extension adds a unique and important dimension to community-engaged research. HEROs are based in their communities and have unique networks that can augment translational research. Likewise, universities can bring much-needed services through research projects to the communities where HEROs live. Researchers and HEROs gain acceptance and trust when the communities realize tangible benefits from research, including financial, social, and health improvements. ${ }^{15}$ An added benefit to the CTSC and the academic institution is the trust built by HEROs stemming from their commitment to long-term engagement with communities to address a range of community needs, including education and clinical service as well as research.

Given tensions and vulnerabilities inherent in the work of HEROs and academic researchers in communities, a set of deliberate approaches taken by HEROs and researchers built mutual credibility. HEROs were then able to vouch for and support researchers within their communities while researchers could share with academic colleagues the value of working with HEROs.

Health extension can facilitate alignment of initiatives with the strategic aims of an academic health center as an engaged university. HEROs are involved in assessing community health priorities and the institution's educational and clinical activities in their respective localities. This link to the broader mission areas builds trust between the communities and the HEROs, thereby enabling the HEROs to be more effective in advocating for research that aligns with community priorities.

We have outlined how a partnership between health extension agents and researchers at an academic CTSA can increase community-based research. For all joint projects developed so far, we have been able to align community health priorities with academic research priorities, that is, adoles- 
cent obesity prevention, mental health services, and prescription opioid use. Next steps include developing a transparent dissemination mechanism, a feedback loop, to inform communities how studies performed in their communities. The ultimate test of effectiveness will be whether or not the health of studied communities and populations improves. Such studies are being planned as part of our institutional vision. ${ }^{11}$

To see this article online, please go to: http://jabfm.org/content/ 30/1/94.full.

\section{References}

1. Institute of Medicine. The CTSA program at NIH: Opportunities for advancing clinical and translational research. Washington, DC: The National Academies Press, Institute of Medicine; 2013.

2. Williams RL, Rhyne RL. No longer simply a practice-based research network (PBRN): Health improvement networks. J Am Board Fam Med 2011; 24:486-88.

3. Norman N, Bennet C, Cowart S, et al. Boot camp translation: A method for building a community solution. J Am Board Fam Med 2013;26:254-63.

4. Oetzel JG, Zhou C, Duran B, et al. Establishing the psychometric properties of constructs in a community-based participatory research conceptual model. Am J Health Promot 2015;29:e188-e202.

5. Phillips RL, Kaufman A, Mold JW, et al. The primary care extension program: A catalyst for change. Ann Fam Med 2013;11:173-8.

6. Extension. United States Department of Agriculture, National Institute of Food and Agriculture. Available from: https://nifa.usda.gov/extension. Accessed April 7, 2016.

7. Health extension toolkit website. Available from: http://www.healthextensiontoolkit.org. Accessed April 7, 2016.

8. Kaufman A, Powell W, Alfero C, et al. Health extension in New Mexico: An academic health center and the social determinants of disease. Ann Fam Med 2010;8:73-81.

9. Rogers E. Diffusion of Innovations. New York, NY: Free Press; 1962.

10. Schroeder SA. We can do better-Improving the health of the American people. N Eng J Med 2007; 357:1221-8.

11. Kaufman A, Roth PB, Larson RL, et al. Vision 2020 measures University of New Mexico's success by health of its state. Am J of Prev Med 2015;48:108-15.

12. Soto Mas F, Cordova C, Murrieta A, et al. A multisite community-based health literacy intervention for Spanish speakers. J Community Health 2015;40: 431-38.

13. Crisanti AS, Pasko DK, Pyeatt C, Silverblatt H, Anastasoff J. Dissemination challenges associated with mental health first aid in New Mexico: Insights from instructors. J Rural Ment Health 2015; 39:13-21.

14. Grumbach K, Mold JW. A health care cooperative extension service: transforming primary care and community health. JAMA 2009;301:2589-91.

15. Michener L, Cook J, Ahmed SM, Yonas MA, Coyne-Beasley T, Aguilar-Gaxiola S. Aligning the goals of community-engaged research: Why and how academic health centers can successfully engage with communities to improve health. Acad Med 2012;87:285-91. 